\title{
EFFICACY OF LOW-DOSE TOCILIZUMAB ON RELAPSING ADULT-ONSET STILL'S DISEASE
}

\author{
Xavier Vandemergel ${ }^{1}$, Frédéric Vandergheynst ${ }^{2}$
}

\begin{abstract}
Department of General Internal Medicine, Centres Hospitaliers Jolimont, Nivelles, Belgium ${ }^{1}$ and CUB Hôpital Erasme,
\end{abstract} Nivelles, Belgium²

Summary: Still's disease is an inflammatory disorder of unknown etiology. First-line therapy is based on corticosteroids and non-steroidal anti-inflammatory drugs (NSAIDs) but the frequency of relapses and corticosteroid-induced adverse events are limiting factors. The efficacy of intravenous tocilizumab (TCZ) has been shown at a dose of $8 \mathrm{mg} / \mathrm{kg}$ but the corticosteroid-sparing effect of intravenous low-dose TCZ followed by subcutaneous (SC) injection in the course of the disease has been poorly investigated. We report the case of a 28-year old Caucasian woman presenting a relapse of Still's disease eleven months after diagnosis under treatment with $6 \mathrm{mg}$ of methylprednisolone. TCZ at a dose of $4 \mathrm{mg} / \mathrm{kg}$ every 2 weeks was combined with $32 \mathrm{mg}$ of methylprednisolone, followed by $162 \mathrm{mg} \mathrm{SC}$ every 3 weeks. Evolution was rapidly favourable with a decrease in corticosteroid doses. We reviewed previously published cases.

Keywords: Still's disease; Tocilizumab; Relapse

\section{Introduction}

Still's disease is a systemic inflammatory disorder of unknown etiology. The term "Still's disease" has been first used in 1971 to describe a series of adult patients with clinical features similar to those found in children with systemic juvenile idiopathic arthritis but who did not meet the criteria for rheumatoid arthritis (1). Clinical manifestations include fever, skin rash, arthralgia and arthritis, sore throat, lymphadenopathy, pericarditis and pleural effusion (2). Laboratory findings include leukocytosis, increase in c-reactive protein (CRP) level and sedimentation rate, and hyperferritinemia (2). The first-line therapy is based on corticosteroids and non-steroidal anti-inflammatory drugs (NSAIDs) but the frequency of relapses and corticosteroid-induced adverse events are limiting factors. High levels of proinflammatory cytokines such as interleukin-1 (IL1), IL6, tumour necrosis factor-alpha (TNF $\alpha)$ or interferon-gamma (IFN $\gamma)$ support the use of biotherapies, including anakinra (3) and tocilizumab (4).

The efficacy of intravenous tocilizumab has been shown at a dose of $8 \mathrm{mg} / \mathrm{kg} / \mathrm{month}$ (5). However, the corticosteroid-sparing effect of low-dose tocilizumab in the course of the disease is not well established.

We report the case of a patient with relapsing adult-onset Still's disease (AOSD) who showed a favourable evolution first under low-dose tocilizumab then under subcutaneous injections (162 mg every 3 weeks) corresponding of a cumulative dose of $3.6 \mathrm{mg} / \mathrm{kg} / \mathrm{month}$. We also reviewed the literature to identify similar cases.

\section{Case report}

A 28-year old Caucasian woman without relevant past medical history was diagnosed with AOSD in May 2014 based on the presence of fever, evanescent rash, arthralgia, sore throat and myalgia. She had leukocytosis $\left(14,620\right.$ cells $\left./ \mathrm{mm}^{3}, 12,590 \mathrm{PMN} / \mathrm{mm}^{3}\right)$ with elevated CRP $(243 \mathrm{mg} / \mathrm{L})$ and erythrocyte sedimentation rate $(49 \mathrm{~mm} / \mathrm{h})$. The ferritin level was $2,372 \mu \mathrm{g} / \mathrm{L}$. The diagnosis of AOSD was made based on the Yamaguchi's criteria.

She received methylprednisolone at a dose of $0.5 \mathrm{mg} / \mathrm{kg}$ and NSAIDs. The evolution was favourable with a rapid decrease in inflammatory parameters and clinical improvement. The corticosteroid dose was progressively tapered. Eleven months after diagnosis, while receiving $6 \mathrm{mg}$ of methylprednisolone, the patient relapsed with fever, arthralgia, myalgia, sore throat and elevation in inflammatory parameters (leukocytosis: 27,470 cells $/ \mathrm{mm}^{3}, 26,130 \mathrm{PMN} / \mathrm{mm}^{3}$, CRP: $126 \mathrm{mg} / \mathrm{dL}$, ferritin level: $738 \mu \mathrm{g} / \mathrm{L})$. She then received $32 \mathrm{mg}$ of methylprednisolone but to prevent corticosteroid-induced adverse events (fluid retention and Cushingoid side effects), tocilizumab was administered at a dose of $4 \mathrm{mg} / \mathrm{kg}$ every two weeks with a total of four intravenous doses.

Two months after the first administration of tocilizumab, the dose of methylprednisolone was reduced to $8 \mathrm{mg} / \mathrm{day}$. At that time, the DAS28 CRP score was 2.7 (3.77 at the time of the first tocilizumab administration). No adverse event was induced by tocilizumab. She then received subcutaneously $162 \mathrm{mg}$ of tocilizumab every 3 weeks. The evolution was favourable and the corticosteroid dose was tapered to 


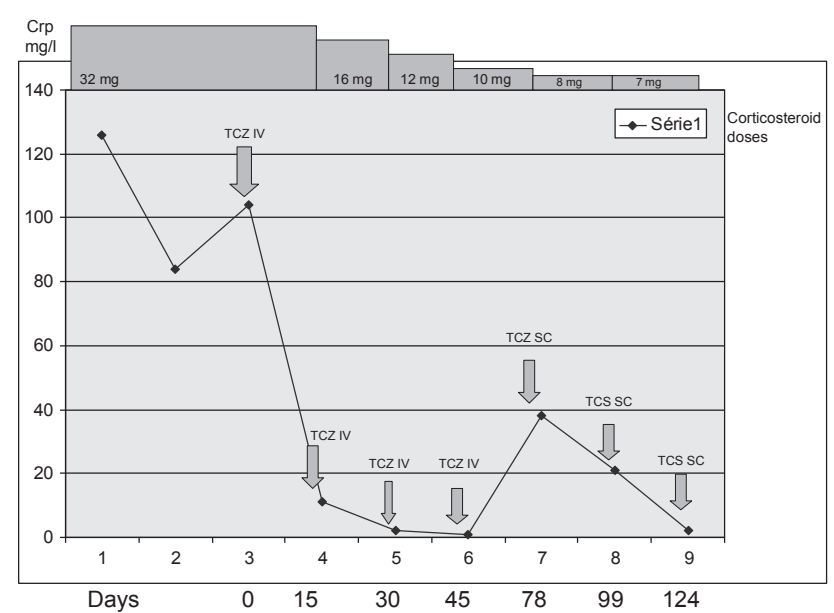

Fig. 1: Evolution of the c-reactive protein level according to the corticosteroid dose.

$6 \mathrm{mg} /$ day three months after the first administration of tocilizumab. The evolution of inflammatory parameters and corticosteroid doses is shown in figure 1. The ferritin levels rapidly decreased from $1,060 \mu \mathrm{g} / \mathrm{L}$ at the time of the first intravenous tocilizumab injection, to $82 \mu \mathrm{g} / \mathrm{L}$ at the time of the first subcutaneous tocilizumab injection and $60 \mu \mathrm{g} / \mathrm{L}$ on Day 124. On Day 124, the DAS28 CRP score was 2.76.

\section{Discussion}

AOSD is an inflammatory disorder characterized by high levels of proinflammatory cytokines such as IL1, IL6, IL18, TNF $\alpha$ and IFN $\gamma$ (6). The first-line therapy is based on corticosteroids, and often long-term high doses are required with their well-known adverse events (7). In an attempt to provide a corticosteroid-sparing effect, disease-modifying antirheumatismal drugs (DMARDs) such as methotrexate have been tested (8). Other drugs, including cyclosporin A, leflunomide, azathioprine, hydroxychloroquine, D-penicillamine, tacrolimus, mycofenolate mofetyl and intravenous immunoglobulins have also been tested in small case series and case reports $(9,10,11,12)$.

The rationale for the use of the anti-IL6 receptor antibody, tocilizumab, in AOSD is based on the central role of IL6 in the inflammatory process (13). IL6 is a pleiotropic cytokine involved in immunoglobulin production, B-cell, cytotoxic T-cell and macrophage differentiation, T-cell proliferation, hematopoiesis modulation, and hepatocyte stimulation to produce acute-phase proteins such as CRP (5). High IL6 levels have been observed in the blood of AOSD patients and have been shown to correlate with the disease activity (14). Tocilizumab is a humanized antihuman monoclonal IL6 receptor antibody whose efficacy has been proven in patients with rheumatoid arthritis (15) and juvenile idiopathic arthritis. Its efficacy has also been shown in small series of AOSD patients (16-18) with various administration methods but $8 \mathrm{mg} / \mathrm{kg}$ were used in most cases. Cipriani et al (17) have shown a clinical and biological improvement in 11 AOSD patients treated with $8 \mathrm{mg} / \mathrm{kg}$ every 4 weeks and a corticosteroid-sparing effect while no adverse events have been reported.

Furthermore, in their series of 14 patients treated with $8 \mathrm{mg} / \mathrm{kg}$ every 4 weeks, Puéchal et al have shown that the DAS28 score dropped from 5.61 to 3.21 at 3 months and to 2.91 at 6 months (16). An improvement in all disease activity scores was observed. The systemic symptoms, including fever and rashes, resolved in $86 \%$ of patients and at 6 months, the mean prednisone dose was reduced to $10.3 \mathrm{mg} /$ day. They have shown no correlation between the tocilizumab dose and the decrease in corticosteroid dose (some patients received $8 \mathrm{mg} / \mathrm{kg}$ every 4 weeks and others every 2 weeks). The following adverse events related to tocilizumab have been reported: necrotizing angiodermatitis in one patient, and chest pain and chills at the time of each administration in one patient leading to tocilizumab discontinuation.

Tocilizumab is commonly used in patients with refractory diseases previously treated with other immunosuppressant drugs. In the study by Puéchal et al (16), all patients had previously received methotrexate and anakinra and in the study by Elkayam (18), the mean number of previously used DMARDs was 3.6. Thus, it remains unknown whether lower doses are effective in mild forms without requiring the use of immunosuppressive drugs. The high cost of tocilizumab should also be noted and could be a rationale for considering the use of lower doses of tocilizumab, in particular when the cost of tocilizumab off-label use is not supported by national insurance reimbursements like in Belgium. Another Belgian specificity which contributed to the choice of tocilizumab is the unavailability of anakinra. Thus, the use of lower doses (i.e. $4 \mathrm{mg} / \mathrm{kg}$ ) may be an option.

We identified four other cases of AOSD patients who received low-dose tocilizumab $(4 \mathrm{mg} / \mathrm{kg})$ in the literature (Table 1). Nakahara et al have reported the case of a 24-year old man with refractory disease (19). All DMARDs and immunosuppressive drugs had been discontinued before tocilizumab injection. They have shown that the CRP level normalized one week after administration of a single dose. They have then increased the dose to $6 \mathrm{mg} / \mathrm{kg}$ then to $8 \mathrm{mg} / \mathrm{kg}$. After injection of the 15th dose of tocilizumab, the patient experienced deep venous thrombosis and massive hematochezia. At that time, the prednisone dose was of $12.5 \mathrm{mg} /$ day. Iwamoto et al (20) have reported the case of a 23-year old AOSD woman whose flares recurred when the prednisolone dose was reduced to 9-20 mg/day. They have shown a dramatic improvement in both systemic and joint symptoms without any serious adverse event. Ortiz et al (17) have reported 2 cases who had received a treatment regimen of $4 \mathrm{mg} / \mathrm{kg}$ every 4 weeks. Both patients had previously received methotrexate and other immunosuppressive drugs (cyclosporin A, anakinra). They have observed a clinical response and a reduction in glucocorticosteroid doses in both cases. 
Tab 1: Patients with Still's disease treated with $4 \mathrm{mg} / \mathrm{kg}$ of Tocilizumab identified in the literature compared to our case.

\begin{tabular}{|c|c|c|c|c|}
\hline & Ortiz-Sanjuan (17) & Nakahara (20) & Iwamoto (21) & Present case report \\
\hline $\mathrm{N}$ & 2 & 1 & 1 & 1 \\
\hline Age & & 35 & 23 & 28 \\
\hline Dose interval & 4 weeks & 1 week & 2 weeks & 2 weeks \\
\hline $\begin{array}{l}\text { Interval between diagnosis } \\
\text { and TCZ initiation }\end{array}$ & $\begin{array}{l}1.4 \text { years } \\
0.4 \text { years }\end{array}$ & 11 years & 25 months & 11 months \\
\hline $\begin{array}{l}\text { Previously cumulated } \\
\text { prednisolone dose }\end{array}$ & $?$ & $?$ & $?$ & $4.5 \mathrm{~g}$ \\
\hline $\begin{array}{l}\text { Other previous immuno- } \\
\text { suppressive drugs }\end{array}$ & $\begin{array}{l}\text { Case 1: MTX, CyA, } \\
\text { Anakinra } \\
\text { Case 2: MTX }\end{array}$ & $\begin{array}{l}\text { MTX, bucillamine, gold } \\
\text { salts, sulfasalazine, AZT, } \\
\text { CyA }\end{array}$ & $\begin{array}{l}\text { MTX, gold salts, } \\
\text { MTX, CyA, } \\
\text { plasmapheresis }\end{array}$ & None \\
\hline Concomitant drugs & $\begin{array}{l}\text { Case 1: GC } \\
\text { Case 2: MTX }\end{array}$ & GC & GC & $\mathrm{GC}$ \\
\hline Outcome & $\begin{array}{l}\text { Clinical response } \\
\text { and reduction in GC } \\
\text { in both cases }\end{array}$ & $\begin{array}{l}\text { Clinical response } \\
\text { and GC discontinuation }\end{array}$ & $\begin{array}{l}\text { Clinical response } \\
\text { and reduction in GC }\end{array}$ & $\begin{array}{l}\text { Clinical and bio- } \\
\text { logical response. } \\
\text { Reduction in GC }\end{array}$ \\
\hline Relapse & No & $\begin{array}{l}21 \text { months after TCZ } \\
\text { discontinuation }\end{array}$ & - & - \\
\hline Adverse events & None & $\begin{array}{l}\text { Deep vein thrombosis } \\
\text { Massive hematochezia }\end{array}$ & None & None \\
\hline Number of IV doses & & $\begin{array}{l}1 \text { dose of } 4 \mathrm{mg} / \mathrm{kg} \text { followed } \\
\text { by } 13 \mathrm{doses} \text { of } 6 \mathrm{mg} / \mathrm{kg} \\
\text { and } 8 \mathrm{mg} / \mathrm{kg} \text { thereafter } \\
\text { followed by a } 21 \text {-month } \\
\text { remission. Readministra- } \\
\text { tion of } 8 \mathrm{mg} / \mathrm{kg} \text { thereafter }\end{array}$ & 13 & 4 \\
\hline
\end{tabular}

Abbreviations: AZT: azathioprine; CyA: cyclosporin A; GC: glucocorticosteroids; IV: intravenous; MTX: methotrexate; TCZ: tocilizumab

Our case presented several specific features: it was the first case in which no concomitant DMARDs were used, showing that the early use of low-dose tocilizumab was effective to achieve remission. Moreover, the third dose was very low $(3.5 \mathrm{mg} / \mathrm{kg})$ and appeared as effective as higher doses and just before the SC administration, the CRP level was slightly elevated with a rapid decrease after SC TCZ injection which suggests that SC TCZ could not only maintain a stable disease activity but also suppress active disease. Tocilizumab induced a rapid clinical and biological response and the administration of subcutaneous injections every 3 weeks $(162 \mathrm{mg})$ appeared effective.

In conclusion, this case report supports the concept that AOSD may be managed with tocilizumab doses lower than the $8 \mathrm{mg} / \mathrm{kg} / \mathrm{month}$ classically used in previously published refractory cases. It should however be noted that in our patient, tocilizumab was used "early" for its steroid-sparing effect and not as a third- or fourth-line therapy in a refractory case.

\section{Acknowledgements}

We thank Roche Belgium for having gracefully provided tocilizumab.

\section{References}

1. Still's disease in the adult. Bywaters EG Ann Rheum Dis 1971; 30 (2): 121.

2. Pouchot J, Sampalis JS, Beaudet F, Carette S, Décary F, Salusinsky-Sternbach M, Hill RO, Gutkowski A, Harth M, Myhal D. Adult Still's disease: manifestations, disease course, and outcome in 62 patients. Medicine 1991; 70(2): 118.

3. Fitzgerald AA, Leclerq SA, Yan A, Homik JE, Dinarello CA. Rapid Responses to anakinra in patients with refractory adult-onset Still's disease. Arhtritis Rheum 2005; 52: 1974.

4. de Boysson H, Février J, Nicolle A, Auzary C, Geffray L. Tocilizumab in the treatment of the adult-onset Still's disease : current clinical evidence. Clin Rheumatol 2013; 32: 141-147.

5. Ortiz-Sanjuan F, Blanco R, Calvo-Rio V, et al. Efficacy of tocilizumab in conventional treatment-refractory adult-onset Still's disease: a multicenter retrospective open-label study of thirty-four patients. Arthritis Rheumatol 2014; 66: 1659.

6. Jamilloux Y, Gerfaud-Valentin M, Henry T, Sève P. Treatment of adult-onset Still's disease: a review. Therapeutics and Clinical Risk Management 2015; 11: 33-43.

7. Curtis JR, Westfall AO, Allison J, et al. Population-based assessment of adverse events associated with long-term glucocorticoid use, Arthritis Rheum 2006; 55(3): 420.

8. Fautrel B, Borget C, Rozenberg S, et al. Corticosteroid sparing effect of low dose methotrexate treatment in adult Still's disease. J Rheumatol 1999; 26(2): 373.

9. Franchini S, Dagna L, Salvo F, Aiello P, Baldissera E, Sabbadini MG. Efficacy of traditional and biologic agents in different clinical phenotypes of adult-onset Still's disease. Arthritis Rheum 2010; 62: 2530-2535.

10. Mitamura M, Tada Y, Koarada S, et al. Cyclosporin A treatment for Japanese patients with severe adult-onset Still's disease. Mod Rheumatol 2009; 19: 57-63.

11. Nakamura H, Odani T, Shimizu Y, Takeda T, Kikuchi H. Usefulness of tacrolimus for refractory adult-onset Still's disease: report of 6 cases. Mod rheumatol 2014; 18: 1-5.

12. Bennett AN, Peterson P, Sangle S, et al. Adult onset Still's disease and collapsing 
glomerulopathy: successful treatment with intravenous immunoglobulins and mycophenolate mofetil. Rheumatology (Oxford) 2004 Jun; 43(6): 795-9.

13. Tanaka T, Kishimoto T. Targeting Interleukin-6: All the way to treat autoimmune and inflammatory disease. Int J Biol Sci 2012; 8: 1227-1236.

14. Hoshino T, Ohta A, Yang D, et al. Elevated serum interleukin-6, interferon-gamma and tumor necrosis-alpha levels in patients with adult Still's disease. J Rheumatol 1998; $25: 396-8$.

15. Rueda Gotor J, Blanco Alonso R. Tocilizumab in rheumatoid arthritis. Rheumatol Clin 2011; 6: 29-32.

16. Puéchal X, De Bandt M, Berthelot JM, et al. Tocilizumab in Refractory Adult Still's Disease. Arthritis Care Research 2011; 1: 155-9.
17. Cipriani P, Ruscitti P, Carubbi F, et al. Tocilizumab for the treatment of Adult-onset Still's disease: Results from a case series. Clin Rheumatol 2014; 33: 49-55.

18. Elkayam O, Jiries N, Dranitzki Z, et al. Tocilizumab in adult-onset Still's disease: The Israeli Experience. The Journal of Rheumatology 2014; 41: 244-247.

19. Nakahara H, Mima T, Yoshio-Hoshino N, Matsushita M, Hashimoto J, Nishimoto N. A case report of a patient with refractory adult-onset Still's disease who was succesfully treated with Tocilizumab over 6 years. Mod Rheumatol 2009; 19: 69-72.

20. Iwamoto M, Nara H, Hirata D, Minota S. Humanized monoclonal anti-interleukin-6 receptor antibody for treatment of intractable adult-onset Still's disease. Arthritis Rheumat 2002; 46: 3388-9.

Received: $13 / 10 / 2015$

Accepted in revised form: $23 / 11 / 2015$

\section{Corresponding author:}

Dr Xavier Vandemergel, Service de Médecine Interne, Centres Hospitaliers Jolimont, 1 Rue Samiette, 1400 Nivelles, Belgium; email: Xavier.Vandemergel@jolimont.be 